\title{
Representation of LGBTQ Communities in the Grand Theft Auto Series
}

\section{Introduction}

In recent years there have been increasing demands for visibility and representation of minority groups within the entertainment industry. This has coincided with a rise in legal and civil protections, and a greater societal awareness of minority groups within the United Kingdom (UK). However, representation and visibility of lesbian, gay, bisexual, transgender and queer (LGBTQ) communities is currently being contested within the UK. Protests across the UK, but primarily concentrated within Birmingham have focused on censoring LGBT visibility within education (Colliver, 2018). These protests signify a social climate which seeks to roll-back equality and diversity initiatives and render minority groups invisible. Although there has been growing levels of visibility of LGBTQ communities within a number of different social spheres, it is important to interrogate the accuracy of the representations and identify harmful stereotypes which are perpetuated through mass media forms. Whilst issues of diversity and equality span a number of different identity characteristics, this chapter will be focusing solely upon issues of gender and sexuality within games.

Undeniably, the gaming industry is hugely popular (Bernal-Merino, 2014) and millions of people engage in gaming on a daily basis (Madigan, 2016). With the rise of the internet, and the opportunities this opened up for participatory, co-operative online play, gaming is firmly established within society as a key form of entertainment. The motivations for gaming are varied (Kircaburun et al., 2018). The Grand Theft Auto series is arguably one of the most popular game series of all time, with GTA V being the most profitable entertainment product, producing more profit than other games, music and film franchises including Star Wars (Batchelor, 2018). 
GTA V was the third best-selling game in the UK in 2017,4 years after its initial release date (Dring, 2018). This chapter will explore the ways in which LGBTQ communities are represented within the GTA games series and identify some of the key stereotypes that are invoked within gameplay for comedic or satirical effect. This chapter will argue that these stereotypes presented within gameplay are harmful for LGBTQ communities in the 'real world' in which discrimination and violence targeting these communities is a very real, lived issue (Home Office, 2018).

\section{Phobia's and Normativity}

The terms 'phobia' and 'phobic' are used throughout this chapter in relation to gender and sexual minorities. However, it is acknowledged that these terms are difficult to conceptualise and there is contention within academia as to the accuracy of these terms when describing discrimination and violence targeting LGBTQ communities. The word 'homophobia' has largely been replaced by the more accurate term 'heterosexism' (Hill, 2016). Similarly, the term 'cissexism' may be used instead of 'transphobia'. The use of the word 'phobia' to describe a dislike, intolerance or hatred towards gender and sexual minorities may be misleading, in that it suggests that these feelings are irrational. Instead, it is becoming more widely acknowledged that that these feelings of intolerance and dislike may be considered entirely rational based on a social system that privileges heterosexuality and cisgenderism, and these feelings are therefore based in a rational, untreatable system of beliefs. However, the terms 'phobia' and 'phobic' are used throughout this chapter as they are more socially recognisable terms but are conceptualised as a hostility towards the deviation of gender and sexual norms. 
There are a number of institutions and structures within the United Kingdom which privilege and normalise heterosexuality and cisgenderism. Wider government structures, educational establishments and the media industry can all perpetuate inequalities and stereotypes within societies. Through constant reinforcement of the normality of heterosexuality and cisgenderism through wider social structures, individuals negotiate their individual sense of self and identity within a number of hierarchies that relate to gender, sexuality, religion, disability status and race, amongst other things and this creates social 'in-groups' and 'out-groups' (Perry, 2001). Wider social structures therefore reinforce notions of heteronormativity, the assumption that everyone is heterosexual unless stated otherwise, and cisnormativity, the assumption that everyone is cisgender unless stated otherwise. The minoritised 'other' therefore become legitimate targets of ridicule, prejudice and violence, often at the hands of various media forms.

The stereotypical presentations of LGBTQ people within mass media forms, including gaming, may contribute to the social climate within which LGBTQ communities negotiate their identities. It will be argued that living within the confines of a capitalist society encourages profit-making ventures over social responsibility. Therefore, representations of minority groups that perpetuate negative stereotypes about targeted groups may contribute to the climate of fear within which they live. Within the UK, hate crimes targeting LGBTQ people are rising annually (Home Office, 2018). A total of 13,289 hate crimes targeting LGBTQ communities were recorded in the year 2017-2018, with 11,638 targeting lesbian, gay and bisexual people and 1,651 incidents targeting transgender people. However, it must be noted that there are a number of incidents which remain unreported for various reasons including a lack of trust within the police and being unaware they have experienced a 
hate crime. METRO Charity (2014) found that $73 \%$ of their participants agreed that discrimination against LGB people is still a social issue and $90 \%$ agreed that discrimination against transgender people is still common in society. Additionally, $74 \%$ of their participants had experienced name calling and $45 \%$ had experienced harassment or threats and intimidation. It is important to acknowledge these experiences in order to frame this chapter within the social climate of which the video games discussed are played.

\section{LGBTQ Representation in Games}

Whilst this chapter focuses upon the representation of LGBTQ communities within gaming, it is important to acknowledge that gaming constitutes only a section of the UK's media and entertainment industry. Therefore, it is important to contextualise the state of the media and entertainment industry more broadly in order to frame the wider structures within which gaming sits. Both news media and entertainment media have an impact upon the discrimination and prejudice that many LGBTQ people face in their daily lives. The media can often perpetuate prejudices and stereotypes about marginalised groups (Solomon and Kurtz-Costes, 2018). There is already a well-established body of work that explores the persuasive and influential nature of the media in its broadest sense (Green and Brock, 2000; Igartua, 2010; Moyer-Gusé and Nabi, 2010). The ways in which LGBTQ people are represented within the media can impact both LGBTQ and non-LGBTQ people. For LGBTQ people, media representation can significantly impact upon their mental health and sense of identity. For non-LGBTQ people, the media can impact their views and opinions of minority groups, therefore impacting the levels of discrimination and prejudice minority communities experience. 
It cannot be argued that all games seek to present the same level of 'realism' within gameplay. However, despite what genre a game is, most will feature some level of realism in different aspects that relate to the virtual environment of the game (for example, city environment, war environments), the scope for social interaction (often with non-playable characters) and the narrative within which the game is set (Albrechslund, 2007). Therefore, it is unsurprising to find some variation in sexual and gender diversity within games. Game developers may then experience pressure to reflect all levels of diversity within society, particularly if the game is based within a 'real-world' setting. The ways in which minority groups are represented within games is important. Given what we already know about the role of the media and entertainment industry in influencing public perception, the construction of minorities within gaming is likely to influence gamers perceptions of minority groups in the 'real world'. Much like other forms of entertainment including teleivision and film, a lack of diversity in gaming has been identified as a significant issue (Kafai et al., 2016). Similarly, within gaming, when diversity is represented, it is often done in stereotypical, pejorative ways.

However, some games have been applauded for their representation of diverse characters, and the ability for players to customise and control the lives of their characters. 'The Sims' game franchise (EA Games/Maxis, 2004) has arguably revolutionised gender and sexuality in gaming. Same-sex relationships were a possible feature of the game from the very first instalment released in 2000. Since the initial release, 'The Sims' franchise has continually developed gameplay options for LGBTQ characters and 'The Sims 4' now includes same-sex marriage, same-sex adoption and greater control over gender expression including clothing preference and the ability to become pregnant. Not only are players able to create and 
customise characters in these ways, the franchise has also included a number of pre-made characters in same-sex relationships. Despite its progressive features, The Sims franchise has received critique in the sense that it subtly and structurally reinforces heteronormativity through the use of 'maid' services, particularly in The Sims 2. When a player hires a maid service in this game, the non-playable maid will always be of the opposite gender to the person who hired the service. In this sense, it has been argued that heteronormativity is structurally reinforced (Albrechtslund, 2007). Whilst The Sims franchise has been hugely popular and a profitable venture whilst enabling sexual and gender diversity in a respectful way, not all games seek to achieve the same outcome.

Some game franchises have a record of endorsing and perpetuating harmful, dated stereotypes about LGBTQ people. However, it is noted that the game focused on in this chapter represents a different genre and different target audience to The Sims franchise. Despite the different genre and target audience, the Grand Theft Auto series falls into the trap of relying upon stereotypically homophobic, biphobic and transphobic constructions of LGBTQ communities for comedic and entertainment value. Issues of stereotyping has already been explored in relation to criminal and racial stereotypes, with a particular focus on GTA V (Polasek, 2014), released in 2013. This chapter will now move on to explore issues of LGBTQ representation within the GTA series more in-depth.

\section{Grand Theft Auto}

Given the very masculine nature of the 'Grand Theft Auto' series, characterised by violence and aggression, it may be surprising at the amount of LGBTQ representation within the game. However, the representation of LGBTQ communities 
is largely negative, drawing upon outdated, harmful and pejorative stereotypes. One of the key stereotypes that is drawn upon throughout the game series is representing gay men as effeminate, or 'camp'. In 'Grand Theft Auto: IV' (2008) there are a number of non-playable pedestrian characters who are implied to be gay through the dialogue within the game. The pedestrians are coded to move in a more traditionally 'feminine' way and use female voices. Furthermore, players are required to create an online dating profile which also features a number of LGBTQ people. The profiles that are viewable also feed in to this stereotype of femininity. The dating profile for 'French Tom' lists his likes as 'being fabulous' and 'getting pampered'. The dating profile for 'NoBigWillie' lists his dislikes as 'bad dress sense. Bad shoes. Stupid hair'. These types of representation of gay men feed into inaccurate stereotypes that all gay men love fashion, musicals and present themselves in more stereotypically feminine ways (Griffo, 2014). In this sense, stereotypes are drawn upon to provide obvious, comedic effects, at the expense of minority groups.

A number of other obvious stereotypes, puns and innuendos are also drawn upon for comedic effect. In 'Grand Theft Auto: III' (2001) there are a number of pedestrians with dialogue associated with them making several references to The Village People'. The pedestrians can be heard saying phrases such as 'Call the YMCA', 'Looking good, sweetheart' and 'You can sail the seven seas'. Many of the phrases the pedestrians can be heard saying make direct reference to lyrics from songs released by The Village People. However, some of the dialogue is much more explicitly homophobic. Pedestrians can also be heard saying 'get off the road, pansy'. In this sense, the game series not only draws upon the use of puns and

\footnotetext{
${ }^{1}$ The Village people are an American disco group best known for their on-stage costumes, suggestive lyrics and for a number of songs that may now be considered 'gay anthems' including 'Y.M.C.A', 'In the Navy' and 'Macho Man'.
} 
stereotypes for comedic effect, there is also a darker, more explicitly homophobic tone to the game.

Another major theme within the representation of gay men within the game is the sexualisation of homosexuality, reducing a nuanced identity and representing it more simplistically as a sex practice. Historically, gay men have been characterised as promiscuous (Davies et al., 2006) and this was perpetuated socially throughout the 1980's and 1990's during the AIDs epidemic, which was termed 'the gay plague' (Streitmatter, 2008). In 'Grand Theft Auto: San Andreas' (2004) the San Fierro Police can be heard saying phrases such as 'when I kick your ass, I'm going to fuck it', 'first I'm going to beat you up, and then beat you off' and 'I'm going to violate your ass'. Whilst none of the police officers explicitly express their homosexuality, the dialogue is intended to imply that they are. This is implied in the most obvious way through sexual discourse. However, in doing so, gay identities are reduced to a sexual practice, thereby negating LGBTQ people's existence outside of sex.

Similarly, a number of male characters throughout the video game series are portrayed as being sex workers. In 'Grand Theft Auto: IV' (2008) the character 'French Tom' is noted as having a criminal record for selling sex. Within the same game, the character 'Florian Cravic' is also noted as having a criminal record for selling sex. On the other hand, the character Jeremy St Ives is noted as having paid for sex. Despite the gender of the people from whom he purchased sex not being mentioned, it is also noted that several references are made throughout the game that imply he is homosexual. As discussed previously, the reliance upon sexual stereotypes of gay men is overly simplistic and reductive of gay identities. This also feeds into dominant stereotypes of gay men's involvement in sex work. Linked directly to stereotypes that portray gay men as promiscuous, assumptions are often 
made about gay men's involvement with sex work, escorting and this is commonly associated with the transmission of HIV. These tropes are historically grounded within the beliefs of 'sexual perversion' associated with homosexuality (Panfil, 2017). The representation of gay men as 'sexually perverted' or 'sexually criminal' is also apparent in 'Grand Theft Auto: Vice City' (2002) in which two members of the 'White Stallionz Gang', a homosexual gang, threaten to rape two other characters. This dialogue and scene draw upon historic stereotypes of gay men as 'sexual predators' (Knauer, 2016). Representing gay men in this way reinforces negative stereotypes of gay men and also contributes to the dehumanisation of LGBTQ communities.

Features of the game are also more explicitly homophobic. In 'Grand Theft Auto: V' (2013) a video game is featured within radio advertisements named 'Pride not Prejudice' and is described as a first-person shooter game. One advert for the game claims that players can 'save the South against liberals and land prospectors and out homosexuals'. In 'Grand Theft Auto: IV' (2008) the player undertakes a mission to save another character from a homophobe who has been harassing them. Throughout this mission, the dialogue that can be heard includes phrases such as 'What's your problem? Fag lover' and 'Florian, open the door, don't be a fag'. In this sense, a vast amount of homophobic language is present throughout the game. As can be seen, this video game series glamorises violence against, and the murder of LGBTQ people for entertainment purposes.

The virtual environment within which the games are set are also constructed to achieve comedic effect at the expense of minority communities. In 'Grand Theft Auto: III' (2001) a shipping company is featured which is notably called 'Fudge Packing Corporation'. In the same game features a radio-controlled car which is named 'RC Bandit'. Both terms are innuendos and puns that relate to historically 
negative phrases for gay men ('fudge packer' and 'arse bandit'). In 'Grand Theft Auto: San Andreas' (2004) a garden centre named 'Uphill Gardener Centre' is featured in the game, within the Queens district, the district that is noted as the games 'gay neighbourhood'. What can be seen is that the game has a number of features within the virtual environment, that are not directly characters, that seek to mock and 'other' LGBTQ communities.

The Grand Theft Auto series also features a number of transgender characters throughout. Similarly to the representation of gay, lesbian and bisexual characters, the game relies on harmful stereotypes for 'entertainment' value. The first notable transgender character features in 'Grand Theft Auto: Vice City' (2002) and is named 'The Psycho'. The storyline features 'The Psycho' being depicted as obsessed with the games feature band 'Love Fist'. It is not made apparent whether the character is actually transgender and presents as female at all times, but the mission makes it clear to the player that 'The Psycho' presents as female in order gain access to band members. The player receives a mission to 'protect' the band from 'The Psycho' by killing her. A number of negative stereotypes are drawn upon in the creation of this character. The most striking stereotype is apparent in the characters name. Transgender people are routinely constructed as 'mentally ill' (Colliver et al., 2019). Arguably, this has been influenced by medical professions and the appearance of 'gender dysphoria' in the DSM-5 (American Psychiatric Association, 2013). The representation of transgender people as 'mentally ill' reinforces a social hierarchy that constructs transgender people as 'less than' and legitimates discrimination against transgender communities.

The narrative surrounding 'The Psycho' also implies that she presents as female in order to 'deceive' the band mates in order to gain access to them. In this sense, the 
transgender character is presented as being sexually deviant and deceptive. Again, this is a harmful stereotype of transgender women and deception 'has been perhaps the most historically consistent and successful idiom through which transgender rights are abrogated and transgender lives are pathologized, demeaned, or cut short' (Fischel, 2019:99). This is a particularly harmful stereotype to perpetuate as it is often drawn upon to justify violence against transgender people, particularly transgender women. In a study of over seven thousand news stories that focused on the murders of transgender and gender non-conforming people over a fifteen year period, ending in 2005 , found that the dominant media frame 'described the violence as a response to actual or perceived deception of the perpetrator by the transgender person' (Schilt and Westbrook, 2009:445-46). The sexualisation of transgender women is a recurrent theme throughout the game series.

Transgender characters also appear in 'Grand Theft Auto: V' (2013). The most visible transgender people in this segment of the series are sex workers, who can be found in groups, primarily outside of the purchasable gay bar within the game. Both the visual and narrative are designed to imply these sex workers are transgender. They are depicted with primarily muscular bodies, broad shoulders and facial features that are primarily associated with masculinity. The dialogue within the game is also designed to imply that these characters are transgender. As a player, upon approaching a group of transgender sex workers, one of the potential dialogues that can be heard is 'Hello, sir. I mean, madam. I mean, whatever'. The dialogue is constructed to present the characters as gender non-conforming, causing apparent confusion within the playable character. The sexualisation of transgender people is also apparent within the character 'Peach' who can be found working within a chain of strip clubs. The character was voiced by a male actor and this is intended to 
reinforce her transgender identity. She is also the only employee of the strip club who cannot be taken home by the playable character.

This is interesting, as transgender women are presented as both sexual objects within the game, but also as an undesirable sexual partner for men. As has been noted by other scholars (Bartholomaeus and Riggs, 2017) various research has explored the fear of fetishization transgender people may experience and the impact this has on their confidence in pursuing romantic and/or sexual relationships. Whilst many transgender people engage in work in the sex industry, because of many prejudices that transgender women face, in some spaces, sex work is the only profession open to transgender women (Ditmore, 2006). However, the representation of transgender characters in this series does not reflect the complex, nuanced structures that often regulate transgender peoples lives. Instead, easilyidentifiable, harmful stereotypes are reproduced within the game series that reinforces and perpetuates the fetishization of transgender women.

The final notable transgender character within the series features in 'Grand Theft Auto: Vice City Stories' (2006). The character of Reni is also sexualised, as it becomes apparent that although now working in the film industry, her previous career highlights include sex work and pornography. However, as this chapter has already discussed the sexualisation of transgender women within the series, it is key to also consider other ways in which transgender women are presented in the series. One of the missions titled 'So Long Schlong' that the playable character must complete in this game requires them to enable Reni to undergo gender reassignment surgery for the forth time. Whilst additional dialogue within the game may lead to the understanding that Reni is non-binary, the inclusion of multiple surgeries seeks to reinforce the idea that transgender people are confused, unstable cannot make up 
their minds (Colliver et al., 2019). This is another harmful stereotypes that is often drawn upon in order to deny transgender people access to medical interventions.

It is not only characters within the game series that reinforce negative stereotypes. The virtual environment within which the game is located in constructed in a way that mocks transgender people. The visual construction of these 'jokes' primarily relates to gender reassignment surgery. In 'Grand Theft Auto: San Andreas' (2004) a car customisation garage is featured in the game called 'TransFender' and features the tag line 'Body Swap Shop'. Both the name and tag line are constructed to be wordplay around gender reassignment and reinforces the socially recognisable understanding of transgender people as 'swapping' their bodies. A similar theme also features in 'Grand Theft Auto: IV' (2008) in which the in-game postal service is named 'Post Op' and the tag line for the service is 'No Longer Just Mail'. Both are obvious references to gender reassignment surgery. Whilst these may not appear to be explicitly transphobic, they seek to minimise the issue of gender reassignment surgery, capitalising on its perceived 'comedic' value at the expense of transgender communities.

\section{Conclusion}

What becomes clear throughout this chapter is that the Grand Theft Auto series relies on harmful stereotypes relating to LGBTQ populations for comedic, satirical and entertainment value. This, in turn, contributes to a culture of 'othering' and segregating those deemed 'different' from society's heteronormative, cisnormative assumptions. As has been demonstrated by other game franchises such as The Sims, it is possible to positively represent LGBTQ communities whilst maintaining a profitable, yet socially responsible game series. The level of anti-LGBTQ content 
within the game series varies from homoerotic undertones to explicitly and openly homophobic language. It is widely acknowledged that stereotypes can be harmful for minority communities (Beasley and Fischer, 2002; Macgillivray and Jennings, 2008). Stereotypes can be harmful in the sense that they can promote exclusion, discrimination and prejudice at a more individual level, even when perpetuated at a wider, societal level. What becomes clear throughout this chapter, is that the impact of living in a capitalist society that privileges profit over social responsibility leads to gender and sexual minorities being presented within video games based off of harmful stereotypes that perpetuate harms against minority communities in the real world.

\section{References}

Albrechtslund, A. (2007) Gender values in simulation games: Sex and The Sims. In: Proceedings of CEPE 2007: The $7^{\text {th }}$ International Conference of Computer Ethics; Philosophical Enquiry Center for Telematics and Information Technology. San Diego, United States of America. 12-14 July 2007.

American Psychiatric Association. (2013) Diagnostic and Statistical Manual of Mental Disorders. (5 $5^{\text {th }}$ Edn). Virginia: American Psychiatric Publishing.

Bartholomaeus, C. and Riggs, D. (2017) Transgender People and Education. London: Palgrave Macmillan.

Batchelor, J. (2018) GTA V is the Most Profitable Entertainment Product of all Time. Available at: https://www.gamesindustry.biz/articles/2018-04-09-gta-v-is-the-mostprofitable-entertainment-product-of-all-time [Accessed 01 August 2019]. 
Beasley, M. and Fischer, M. (2012). Why they leave: The impact of stereotype threat on the attrition of women and minorities from science, math and engineering majors. Social Psychology of Education. 15(4). Pp. 427-448.

Bernal-Merino, M. (2015). Translation and Localisation in Video Games: Making Entertainment Software Global. London: Routledge.

Colliver, B. (2018). Removing 'No Outsiders' School Lessons is Adding to LGBT People being Targets for Hate Speech and Violence, Warns Social Scientist. Birmingham City University [Blog] 21 March. Available at: https://www.bcu.ac.uk/news-events/news/removing-no-outsider-school-lessons-isadding-to-lgbt-people-being-targets-for-hate-speech-and-violence-warns-socialscientist [Accessed 01 August 2019]

Colliver, B., Coyle, A. and Silvestri, M. (2019) The Online 'othering' of transgender and non-binary people. In: Lumsden, K. and Harmer, E. (eds). Online Othering: Exploring Digital Violence and Discrimination on the Web. London: Palgrave Macmillan. Pp. 215-238

Davies, M., Pollard, P. and Archer, J. (2006). Effects of perpetrator gender and victim sexuality on blame toward male victims of sexual assault. The Journal of Social Psychology. 146(3). Pp. 275-291.

Ditmore, M. (2006). Encyclopedia of Prostitution and Sex Work. (2nd Edn). London: Greenwood Press.

Dring, C. (2018). Revealed: The 100 Best-Selling UK Boxed Games of 2017. Available at: https://www.gamesindustry.biz/articles/2018-01-12-revealed-the-bestselling-uk-boxed-games-of-2017 [Accessed 01 August 2019]. 
Fischel, J. (2019). Screw Consent: A Better Politics of Sexual Justice. California: University of California Press.

Green, M. and Brock, T. (2000). The role of transportation in the persuasiveness of public narratives. Journal of Personality and Social Psychology. 79(5). Pp. 701-721.

Griffo, C. (2014). The Key to Unlocking the Closet Door. London: Balboa Press.

Hill, D. (2016). Transphobia. In: Goldberg, A. (eds) The Sage Encyclopedia of LGBTQ Studies. London: Sage Publications Ltd. Pp. 1271-1272.

Home Office. (2018). Hate Crime: England and Wales, 2017/18. London: Home Office.

Igartua, J. (2010). Identification with characters and narrative persuasion through fictional feature film. The European Journal of Communication Research. 35(4). Pp. 347-373.

Kafai, Y., Richard, G. and Tynes, B. (2016) The need for intersectional perspectives and inclusive designs in gaming. In: Kafai, Y., Richard, G. and Tynes, B. (eds.) Diversifying Barbie and Mortal Kombat: Intersectional Perspectives and Inclusive Designs in Gaming. North Carolina: Lulu.com. Pp. 1-22.

Kircaburun, K., Jonason, P. and Griffiths, M. (2018). The dark tetrad traits and problematic online gaming: The mediating role of online gaming motives and moderating role of game types. Personality and Individual Differences. 135. Pp. 298303.

Knauer, N. (2016). Gay and Lesbian Elders: History, Law and Identity Politics in the United States. London: Routledge. 
Macgillivray, I. and Jennings, T. (2008). A content analysis exploring lesbian, gay, bisexual, and transgender topics in foundations of education textbooks. Journal of Teacher Education. 59(2). Pp. 170-188.

Madigan, J. (2016). Getting Gamers: The Psychology of Video Games and their Impact on the People who Play them. London: Rowman and Littlefield.

METRO Charity. (2014). Youth Chances: Summary of First Findings. London: METRO Charity.

Moyer-Gusé, E. and Nabi, R. (2010). Explaining the effects of narrative in an entertainment television program: Overcoming resistance to persuasion. Human Communication Research. 36(1). Pp. 26-52.

Panfil, V. (2017) The Gang's all Queer: The Lives of Gay Gang Members. New York: New York University Press.

Perry, B. (2001). In the Name of Hate: Understanding Hate Crimes. London: Routledge.

Polasek, P. (2014). A critical race review of Grand Theft Auto V. Humanity and Society. 38(2). Pp. 216-218.

Schilt, K. and Westbrook, L. (2009). Doing gender, doing heteronormativity: Gender normal, transgender people, and the social maintenance of heterosexuality. Gender and Society. 23(4). Pp. 440-464.

Solomon, H. and Kurtz-Costes, E. (2018). Media's influence on perceptions of trans women. Sexuality Research and Social Policy. 15(1). Pp. 34-47.

Streitmatter, R. (2008). From Perverts to Fab Five: The Media's Changing Depiction of Gay Men and Lesbians. London: Routledge. 
